\title{
Acute dairy milk ingestion does not improve nitric oxide-dependent vasodilation in the cutaneous microcirculation
}

\author{
Billie K. Alba ${ }^{1}$, Anna E. Stanhewicz ${ }^{2}$, W. Larry Kenney ${ }^{1,2}$ and Lacy M. Alexander ${ }^{1,2 *}$ \\ ${ }^{1}$ Department of Kinesiology, The Pennsylvania State University, University Park, PA 16802, USA \\ ${ }^{2}$ Center for Healthy Aging, The Pennsylvania State University, University Park, PA 16802, USA \\ (Submitted 14 November 2015 - Final revision received 22 February 2016 - Accepted 11 April 2016 - First published online 16 May 2016)
}

\section{Abstract}

In epidemiological studies, chronic dairy milk consumption is associated with improved vascular health and reduced age-related increases in blood pressure. Although milk protein supplementation augments conduit artery flow-mediated dilation, whether or not acute dairy milk intake may improve microvascular function remains unclear. We hypothesised that dairy milk would increase direct measurement of endothelial nitric oxide (NO)-dependent cutaneous vasodilation in response to local skin heating. Eleven men and women (61 (sEM 2) years) ingested two or four servings ( 473 and $946 \mathrm{ml}$ ) of $1 \%$ dairy milk or a rice beverage on each of 4 separate study days. In a subset of five subjects, an additional protocol was completed after $473 \mathrm{ml}$ of water ingestion. Once a stable blood flow occurred, $15 \mathrm{~mm}-N^{G}$-nitro-L-arginine methyl ester was perfused (intradermal microdialysis) to quantify NO-dependent vasodilation. Red-blood-cell flux (RBF) was measured by laser-Doppler flowmetry, and cutaneous vascular conductance $(\mathrm{CVC}=\mathrm{RBF} / \mathrm{mean}$ arterial pressure) was calculated and normalised to maximum $\left(\% \mathrm{CVC}_{\max } ; 28\right.$ mm-sodium nitroprusside). Full expression of cutaneous vasodilation was not different among dairy milk, rice beverage and water, and there was no effect of serving size on the total vasodilatory response. Contrary to our hypothesis, NO-dependent vasodilation was lower for dairy milk than rice beverage (D: 49 (SEM 5), R: 55 (SEM 5) \%CVC $\mathrm{Cax}_{\max } P<0 \cdot 01$ ). Acute dairy milk ingestion does not augment NO-dependent vasodilation in the cutaneous microcirculation compared with a rice beverage control.

\section{Key words: Dairy milk: Insulin: Microcirculation: Nitric oxide: Vasodilation}

CVD is the leading cause of mortality in the USA and is responsible for approximately $17 \%$ of national healthcare expenditures ${ }^{(1)}$. As such, effective non-pharmacological prevention strategies and early identification of modifiable lifestyle risk factors (e.g. dietary habits) are essential to limit the growing burden of CVD. Bioactive micronutrients and macronutrients in particular may have a preventive and protective effect against disease. Chronic dairy milk consumption is associated with attenuated age-related increases in blood pressure and improved cardiovascular outcomes. Increased dairy milk intake has positive effects on blood pressure ${ }^{(2-6)}$ and measures of conduit-vessel function including pulse-wave velocity $^{(7)}$, and arterial stiffness ${ }^{(8)}$. However, little is known about the mechanisms by which dairy milk consumption may improve vessel function specifically at the level of the microcirculation.

The putative mechanisms mediating improvements in vascular function induced by dairy milk intake are probably complex and may involve the synergistic effects of milk proteins and elemental components. In vitro data indicate that bioactive peptides derived from the two primary milk proteins, whey and casein, exhibit angiotensin-converting enzyme (ACE) inhibitor properties ${ }^{(9-12)}$ and direct antioxidant and radical scavenging activity ${ }^{(13-15)}$. In humans, chronic consumption of these peptides (1-10 weeks) decreases measures of systemic inflammation (IL-6, monocyte chemoattractant protein 1 and $\mathrm{TNF} \alpha)^{(16-18)}$, and the mineral composition in dairy milk (Ca, K and $\mathrm{Mg}$ ) moderately reduces blood pressure ${ }^{(19,20)}$. The common vascular signalling pathway that links each of these purported mechanisms (angiotensin II inhibition, antioxidant properties, anti-inflammatory, etc.) is through increasing nitric oxide (NO) bioavailability. NO is a potent vasoprotective agent produced by the vascular endothelium and is essential for vessel health and function. Reduced NO bioavailability is prevalent in all cases of cardiovascular dysfunction, and precedes the onset of clinically detectable $\mathrm{CVD}^{(21-23)}$. Work conducted in our laboratory and in those of others has demonstrated a reduced NO-dependent vasodilation during local heating in healthy middle-aged ${ }^{(24)}$ and older adults ${ }^{(25)}$. Further, the NO component of the local heating response provides a quantitative assessment of the magnitude of improvements in vascular function when examining the effects of interventions ${ }^{(26,27)}$. Therefore, we would expect our cohort of adults (55-75 years) to have age-related deficits in NO-dependent vasodilation that may be improved by the proposed dietary intervention.

Abbreviations: CVC, cutaneous vascular conductance; NO, nitric oxide; SNP, sodium nitroprusside.

* Corresponding author: L. M. Alexander, fax +1 814865 4602, email lma191@psu.edu 
The cutaneous circulation is an accessible and representative circulation for the in vivo study of mechanisms mediating vascular function and dysfunction in humans ${ }^{(28-30)}$. Deficits in cutaneous function are highly correlated with measures of vessel dysfunction in the coronary and renal circulations ${ }^{(31,32)}$. Moreover, altered cutaneous microvascular function is evident before long-term changes in blood pressure or presentation of clinical symptoms $^{(33)}$. As such, the cutaneous vascular bed has utility for the in vivo examination of molecular mechanisms by which intervention strategies may affect vessel function in humans. The cutaneous circulation has been previously used to study microvascular responses to several nutritional interventions $^{(34-38)}$, including acute oral micronutrient ingestion ${ }^{(36)}$.

Given the epidemiological evidence that increased dairy milk consumption reduces CVD risk across the lifespan ${ }^{(39,40)}$ and the evidence that the mechanisms associated with this decrease converge on the NO pathway, the aim of this study was to determine the mechanistic effect of acute milk consumption on cutaneous microvascular function in healthy older adults (55-75 years). We hypothesised that acute dairy milk consumption (two and four servings) would increase NO-dependent vasodilation in a dose-dependent manner compared with a non-dairy rice beverage control.

\section{Methods}

\section{Subjects}

All protocols were approved by the Institutional Review Board at The Pennsylvania State University and complied with the guidelines of the Declaration of Helsinki. All participants voluntarily provided written and verbal consent before the experiment. Eleven subjects (61 (SEM 2) years; five men, six women) participated in the study. Before participation, subjects underwent a medical screening that included a twelve-lead electrocardiogram, fasting blood chemistry and physical examination. Subjects also completed a 24-h ambulatory blood pressure monitoring while enrolled in the study. Inclusion criteria required a daily dairy milk intake of less than two servings. Daily dairy milk intake was assessed with a modified FFQ specific to dairy milk consumption. Subjects had a 2-d wash-in period of no dairy milk consumption and abstained from alcoholic and caffeinated beverages for $12 \mathrm{~h}$, vigorous physical activity for $24 \mathrm{~h}$ and food for $8 \mathrm{~h}$ before each experiment. All subjects were non-smokers, non-diabetic, non-obese $\left(\mathrm{BMI}<30 \mathrm{~kg} / \mathrm{m}^{2}\right)$ and were not on any prescription medications that may alter vascular function (e.g. statins, antidepressants, antihypertensives, etc.). Women taking hormone replacement therapy were excluded from the study.

\section{Experimental protocol}

On four separate visits, subjects ingested $473 \mathrm{ml}$ (two servings) of dairy milk ( $1 \%$ fat; Giant Eagle), $946 \mathrm{ml}$ (four servings) of $1 \%$ fat dairy milk, $473 \mathrm{ml}$ of a rice beverage (Nature's Promise Original Enriched) or $946 \mathrm{ml}$ of rice beverage with a minimum of 1 week between visits. Although consideration was given to other milk alternatives, we chose a rice beverage as the control beverage given its similarity to dairy milk in nutrient and energy content, as well as the absence of additional ingredients (e.g. soya) that may affect vascular function. A subset $(n 5)$ of subjects also ingested $473 \mathrm{ml}$ of water on an additional visit. The water trial was included to serve as an iso-volumetric, fasted reference value and was not included in the statistical analysis. The treatment order was randomly assigned for each subject. The energy, macronutrient and micronutrient contents of each treatment are displayed in Table 1.

All experiments were performed in a thermoneutral environment with subjects in a semi-supine position. Using a sterile technique, one intradermal microdialysis fibre $(10 \mathrm{~mm}$, 30-kDa membrane limit, MD 2000; Bioanalytical Systems) was placed in the ventral forearm skin. Ice was applied to the forearm for $5 \mathrm{~min}$ to anesthetise the skin before fibre placement. A 25-G needle was inserted into the skin with entry and exit points $2-3 \mathrm{~cm}$ apart. The fibre was threaded through the needle, which was subsequently removed leaving the semipermeable portion of the fibre remaining under the skin. Red-blood-cell flux (RBF), an index of skin blood flow, was measured by a laser-Doppler flowmetry probe placed in a local heating unit (MoorLab, Temperature Monitor SH02; Moor Instruments) directly over the microdialysis membrane. Brachial artery blood pressure was recorded at 5-min intervals (Cardiocap; GE Healthcare) throughout the protocol.

Localised microdialysis pharmaceutical perfusates were dissolved in lactated Ringer's just before use, microfiltered (Acrodisc; Pall) and covered in foil to prevent light degradation. Before baseline data collection, the fibre was perfused ( $2 \mu \mathrm{l} / \mathrm{min}$ ) with lactated Ringer's for $60-90 \mathrm{~min}$ to allow the skin to recover from any trauma caused by the insertion of the microdialysis fibre. Subjects ingested the selected milk treatment after $30 \mathrm{~min}$ of hyperaemia. This time point for consumption was chosen so that the local heating plateau would occur 60-90 min post treatment, which is the time period after milk peptide ingestion when peak intestinal concentrations of bioactive peptides are recovered ${ }^{(41)}$.

Subjects were instrumented with an intravenous catheter after fibre placement for the collection of blood samples. A fasted

Table 1. Micronutrient and macronutrient content of two and four servings of the $1 \%$ fat dairy milk and rice beverage

\begin{tabular}{|c|c|c|c|c|}
\hline & \multicolumn{2}{|c|}{$\begin{array}{l}\text { Per } 2 \text { dairy serving } \\
\text { equivalents }\end{array}$} & \multicolumn{2}{|c|}{$\begin{array}{l}\text { Per } 4 \text { dairy serving } \\
\text { equivalents }\end{array}$} \\
\hline & $1 \%$ milk & Rice beverage & $1 \%$ milk & Rice beverage \\
\hline Serving size (ml) & 473 & 473 & 946 & 946 \\
\hline Energy (kJ) & 920 & 837 & 1841 & 1674 \\
\hline Energy (kcal) & 220 & 200 & 440 & 400 \\
\hline Fat $(\mathrm{g})$ & 5 & 4 & 10 & 8 \\
\hline SFA (g) & 3 & 0 & 6 & 0 \\
\hline Cholesterol (mg) & 30 & 0 & 60 & 0 \\
\hline Protein $(\mathrm{g})$ & 16 & 0 & 32 & 0 \\
\hline Carbohydrates (g) & 24 & 46 & 48 & 92 \\
\hline Sugars (g) & 24 & 30 & 48 & 60 \\
\hline Fibre (g) & 0 & 0 & 0 & 0 \\
\hline $\mathrm{Na}(\mathrm{mg})$ & 260 & 180 & 520 & 360 \\
\hline $\mathrm{Ca}(\mathrm{mg})$ & 600 & 600 & 1200 & 1200 \\
\hline $\mathrm{K}(\mathrm{mg})$ & 740 & 0 & 1480 & 0 \\
\hline
\end{tabular}


blood sample was taken before treatment administration. Blood samples were then taken every 30 min post treatment until the completion of the study. The blood samples were collected in EDTA-treated tubes, which were subsequently refrigerated and centrifuged. The plasma samples were stored at $-80^{\circ} \mathrm{C}$ until future use. Plasma insulin concentrations were measured at baseline and at $90 \mathrm{~min}$ post ingestion using a commercially available ELISA (Mercodia) according to the manufacturer's instructions. Samples were analysed in duplicate with an average $\mathrm{CV}<10 \%$.

Baseline measurements were collected for $20 \mathrm{~min}$ at a local skin temperature of $33^{\circ} \mathrm{C}$. After a stable baseline period, the local skin temperature was increased to $42^{\circ} \mathrm{C}$ at a rate of $0.5^{\circ} \mathrm{C}$ every $5 \mathrm{~s}$. Once a 10-min plateau was reached (approximately $40 \mathrm{~min}$ ), the site was perfused with $15 \mathrm{~mm} \mathrm{~N}^{\mathrm{G}}$-nitro-L-arginine methyl ester (L-NAME; Calbiochem), a non-specific nitric oxide synthase (NOS) inhibitor, at a rate of $4 \mu \mathrm{l} / \mathrm{min}$ to quantify NO-dependent vasodilation $^{(24,42,43)}$. After $10 \mathrm{~min}$ of stable $\mathrm{RBF}$ measurements (approximately $45 \mathrm{~min}$ ), maximal vasodilation was induced by perfusing the fibre with $28 \mathrm{~mm}$-sodium nitroprusside (USP) and increasing the local skin temperature to $43^{\circ} \mathrm{C} \quad(30 \mathrm{~min})$. Work conducted in our laboratory and in those of others has demonstrated that this protocol is highly specific to endothelial nitric oxide synthase (eNOS) production and allows the direct quantification of functional NO-dependent vasodilation in the cutaneous microcirculation $^{(24,44,45)}$

\section{Data acquisition and statistical analysis}

Data were collected with Windaq (DATAQ Instruments) at a frequency of $40 \mathrm{~Hz}$. Cutaneous vascular conductance (CVC) was calculated as RBF divided by mean arterial pressure. Data were normalised to a per cent of maximum CVC. CVC data were averaged over a stable 5 -min period at baseline, the local heating plateau, the L-NAME plateau and maximum vasodilation. NO-dependent vasodilation was calculated as the difference between $\mathrm{CVC}$ at the local heating plateau and $\mathrm{CVC}$ at the post L-NAME plateau and expressed as a percentage of maximum. A three-way repeated-measures ANOVA was used to detect within-subject effects of dietary treatment and serving size on the phases of the local heating response. There was no main effect of serving size on functional vascular measures, and thus the data for the 473- and 946- $\mathrm{ml}$ servings were combined and a nested two-way repeated-measures ANOVA was performed to detect differences between dietary treatment on the parameters of the local heating response (version 9.4; SAS). Bonferroni post hoc corrections were performed to account for multiple comparisons when necessary. Significance was accepted using $\alpha=0 \cdot 05$. Unless otherwise indicated, all values are presented as means and standard errors.

\section{Results}

Subject characteristics are displayed in Table 2.

Fig. 1 depicts an original record of the response to skin local heating.

There were no differences in the local heating plateau between the dairy milk and rice beverage treatments (Fig. 2).
Table 2. Subject characteristics (Mean values with their standard errors; $n 11 ; 5$ male, 6 female)

\begin{tabular}{lcl}
\hline & Mean & SEM \\
\hline Age (years) & 61 & 2 \\
BMI (kg/m²) & $26 \cdot 1$ & $0 \cdot 6$ \\
DBP (mmHg) & 74 & 2 \\
SBP (mmHg) & 125 & 5 \\
HDL (mmol/l) & 1.6 & $0 \cdot 2$ \\
LDL (mmol/l) & $3 \cdot 2$ & 0.3 \\
Total cholesterol (mmol/l) & $5 \cdot 1$ & 0.3 \\
Fasting glucose (mmol/l) & $5 \cdot 3$ & 0.2 \\
HbA1c (\%) & 5.6 & $0 \cdot 1$ \\
\hline
\end{tabular}

DBP, diastolic blood pressure; SBP, systolic blood pressure; HbA1c, glycated $\mathrm{Hb}$.

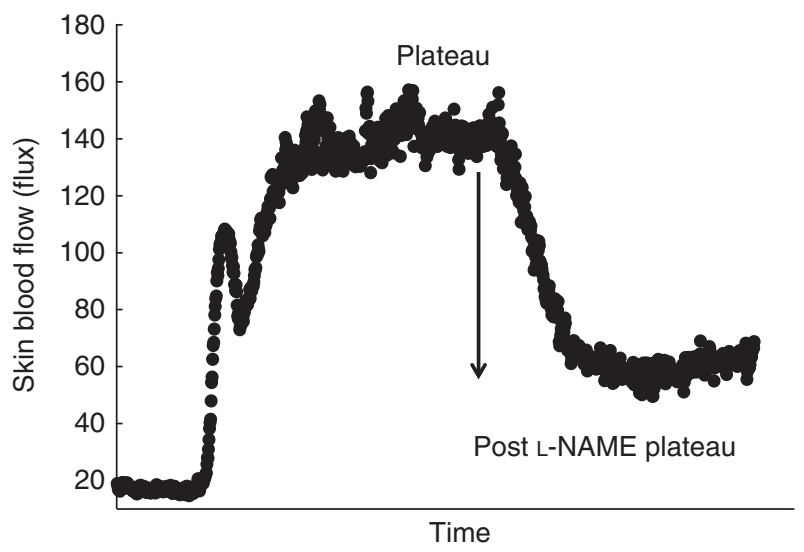

Fig. 1. Representative tracing of the local heating response in one subject. $\downarrow$, Decrease in skin blood flow with nitric oxide synthase inhibition. L-NAME, $N^{G}$-nitro-L-arginine methyl ester.

However, the \%NO-dependent vasodilation was attenuated following dairy milk ingestion compared with the \%NOdependent vasodilation following rice beverage ingestion (R: 49 (SEM 5), D: 55 (sem 5) \%CVC $\max ; P<0 \cdot 01$ ).

To determine whether the insulin responses contributed to the differences in NO-dependent vasodilation between milk treatments, plasma insulin concentrations were measured using the plasma samples from the 90-min time point, which coincided with the timing of $\mathrm{NO}$ quantification during the local heating protocol. The plasma insulin concentration following dairy milk consumption was lower compared with rice beverage consumption for both two and four servings (2D: 84 (SEM 10) pmol/l, 2R: 205 (SEM 20) pmol/l; $P<0 \cdot 001$, 4D: 161 (SEM 37) pmol/l, 4R: 311 (sEM 45) pmol/l; $P<0 \cdot 001$ ). The lower plasma insulin concentrations following the dairy milk treatments were associated with decreased NO-dependent vasodilation (Fig. 3).

\section{Discussion}

The principal finding of this study was that NO-dependent vasodilation was attenuated following acute dairy milk consumption compared with the rice beverage. Despite the local heating plateau being similar between dairy milk and rice beverage, when NO-dependent vasodilation was directly quantified it was reduced 
(a)

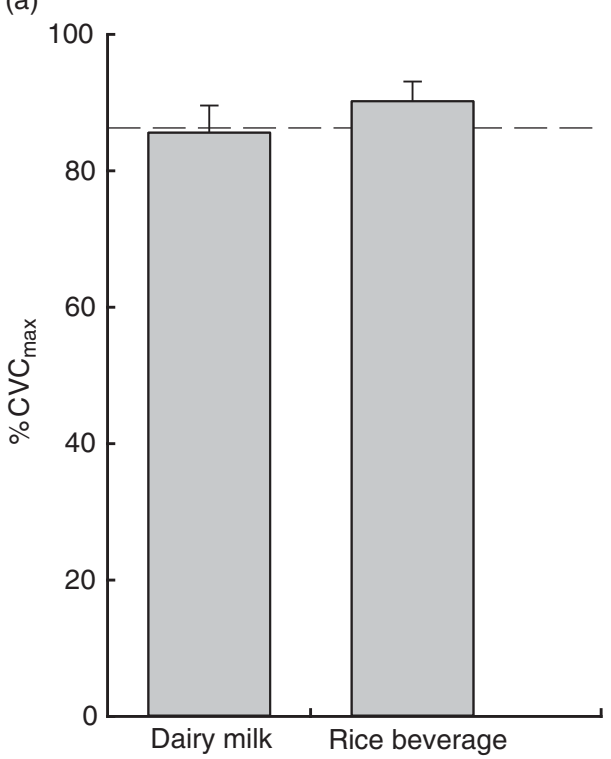

(b)

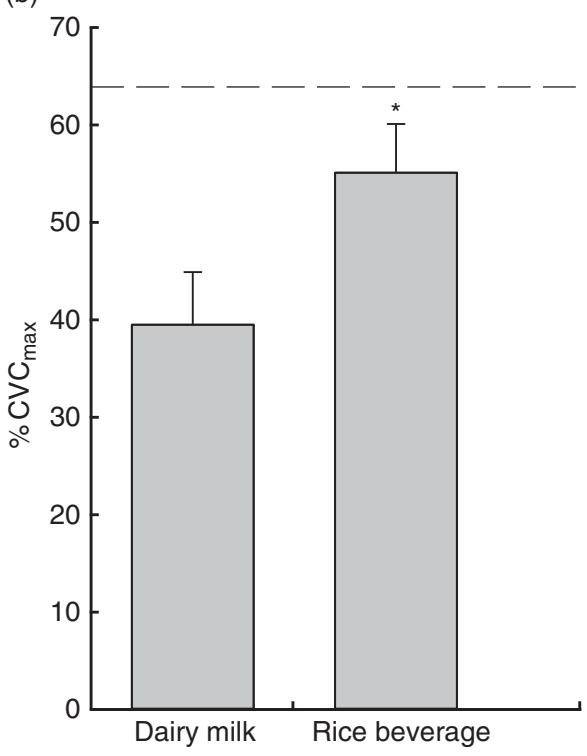

Fig. 2. (a) Local heating plateau and (b) \% nitric oxide (NO)-dependent dilation following dairy milk or rice beverage ingestion. ${ }^{*} P=0.004$ difference $v$. dairy milk. -- , Response in five subjects who completed a water (fasted) trial, included for reference. CVC, cutaneous vascular conductance.

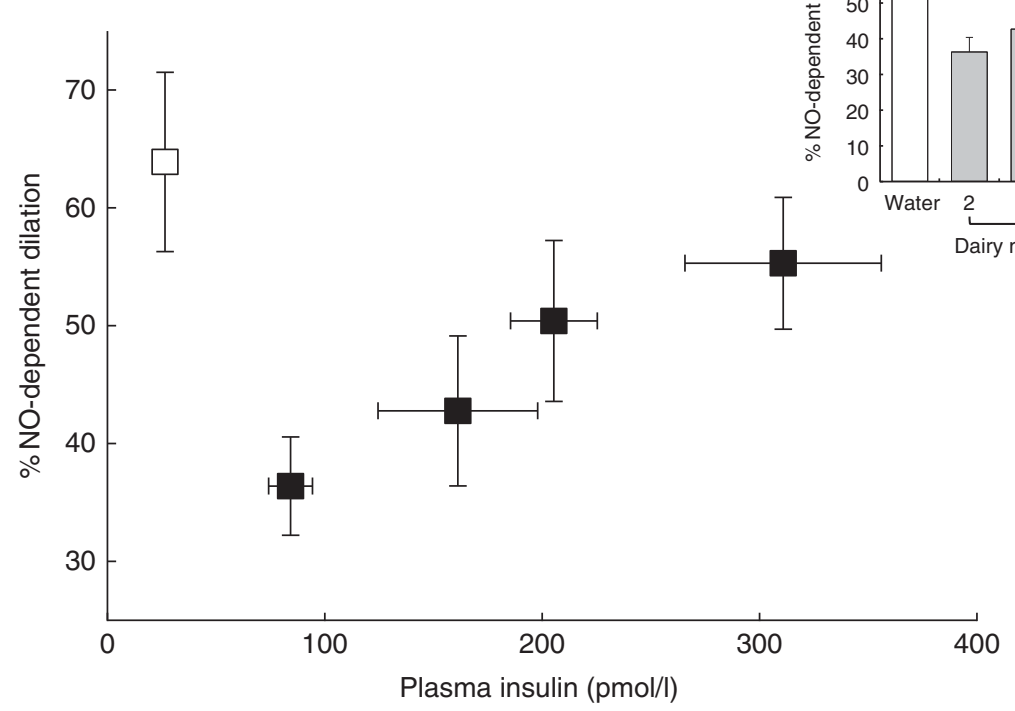

Fig. 3. Plasma insulin response and corresponding \% nitric oxide (NO)-dependent dilation $90 \mathrm{~min}$ following consumption of two or four servings of dairy milk or rice beverage. The inset depicts the \%NO-dependent vasodilation for the dairy milk and rice beverage separated by dose (two servings: $473 \mathrm{ml}$ and four servings: $946 \mathrm{ml}$ ). $\square$, Response in five subjects who completed a water (fasted) trial, included for reference.

following dairy milk consumption. Plasma insulin concentrations were also lower following dairy milk ingestion and were associated with decreased NO-dependent vasodilation during local skin heating. Contrary to our hypothesis, these data suggest that acute dairy milk consumption does not augment NO-dependent vasodilation in the cutaneous microcirculation. It is important to note that although it appears that NO-dependent vasodilation following rice beverage consumption is unchanged compared with the fasted (water) trial and
NO-dependent vasodilation following dairy milk consumption is attenuated relative to the fasted state, we cannot determine how these data compare to a normal unfasted state based on our results.

The macronutrient content of the dairy milk and rice beverage differ substantially, which may explain differences observed in the present study. Although the dairy milk and rice beverage match closely in fat content, dairy milk has a lower carbohydrate content and thus a low glycaemic index 
compared with the rice beverage ${ }^{(46)}$, and was associated with a smaller insulin plasma response. Insulin induces vasodilation in the cutaneous microcirculation ${ }^{(47-49)}$ through an NOdependent mechanism ${ }^{(47)}$. In the present study, plasma insulin concentrations were lower following the dairy milk treatments relative to their respective iso-volumetric rice beverage treatments. Moreover, the lower plasma insulin concentrations following the dairy milk treatments were associated with reduced NO-dependent vasodilation. The low plasma insulin and high NO-dependent vasodilation following water ingestion may appear to conflict with the proposed role of insulin in augmenting NO-dependent vasodilation. However, we expect a low plasma insulin concentration following water ingestion because of the lack of macronutrients in water. At the same time, we expect a high NO-dependent vasodilation following water ingestion because of the absence of a postprandial hyperglycaemic response, which includes increases in oxidant species and thus reductions in NO bioavailability ${ }^{(50)}$.

Dairy milk proteins have a demonstrated positive benefit on vascular function in both animal and human models ${ }^{(16,51-54)}$. For example, milk peptides in hypertensive rat models show improvements in endothelial-dependent vasodilation, both in vitro $^{(51)}$ and following a 6-week supplementation ${ }^{(52)}$, and eNOS expression following 5-d to 6-week supplementations ${ }^{(52,55)}$. In humans, vascular function, measured by flow-mediated vasodilation in the brachial artery ${ }^{(53,54)}$, and reactive hyperaemia $^{(16,53)}$ are improved after $1-8$ weeks of milk peptide ingestion. Reasons for the discrepancy between these findings and the present study include differences in the form of the milk proteins and the acute nature of the intervention. Most studies examining the effects of milk proteins on vascular function have used isolated milk protein hydrolysate $e^{(16,52-55)}$ instead of fluid milk or other dairy products. Isolated milk peptides and dairy milk may differ in their resistance to peptidases during digestion and ability to transport across the intestinal wall in an active form. In addition, many of these studies have been chronic interventions

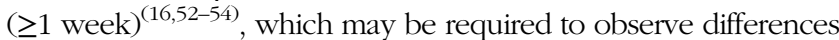
in vascular function. Ballard et al ${ }^{(56)}$ conducted a study examining acute low-fat milk consumption on vascular function and found that, unlike rice beverage ingestion, dairy milk ingestion maintained endothelial function by reducing the postprandial hyperglycaemia. Differences from the present study include measurement of conduit arterial function, quantified by brachial artery flow-mediated dilation, instead of microvascular function. Moreover, the study by Ballard et al. was conducted on individuals with metabolic syndrome, which may also explain the differences between the two studies

It is important to note that in the present study the overall vasodilation response to local heating was not different between dairy milk and rice beverage treatments, or different compared with the fasted (water) trial. There is a great deal of redundancy in the mechanisms contributing to the cutaneous vasodilator response to local heat ${ }^{(57-60)}$, and our data do not suggest that acute milk ingestion reduces vascular function. Rather, because there was no change of the local heating plateau, the acute exposure to higher insulin concentrations may have modulated the NO contribution to the total vasodilator response following rice beverage ingestion.
One of the strengths of the current study is that we directly quantified functional NO-dependent vasodilation using an eNOS-dependent stimulus ${ }^{(24)}$. In doing this, we were able to dissect out the amount of vasodilation due to $\mathrm{NO}$ with our specific dietary treatments. This is an initial first step in determining the direct acute effects of dairy milk on vascular function. The possibility remains that chronic dairy milk consumption improves endothelial function over a longer time course.

\section{Limitations}

Intestinal recovery of milk peptides occurs within 60-90 min of consumption $^{(41)}$, and acute milk consumption has been shown to alter conduit arterial function within 90 min post ingestion ${ }^{(56)}$. A chronic milk intervention may be appropriate to elucidate the effects of dairy milk intake on microvascular function, as it would allow for sufficient time for the milk peptides to act on the peripheral vasculature and would not be masked by an acute insulin response.

Because the proposed mechanisms by which dairy milk consumption may affect blood vessel function converge on the NO pathway, we focused primarily on NO-dependent mechanisms of microvascular function. However, it is possible that NO-independent mechanisms mediate improvements in vascular function observed with milk peptide consumption. Evidence for contribution from other mechanisms has been documented by increases in resistance vessel blood flow in response to reactive hyperaemia, a measure that is largely independent of NO, after milk peptide consumption ${ }^{(53)}$. In vitro casein-derived tripeptides induce endothelial-dependent dilation, an effect that is reduced with $\mathrm{K}^{+}$channel inhibition, NOS inhibition and bradykinin $\mathrm{B} 2$ receptor antagonists, suggesting additional roles for other vasodilatory substances including endothelium-derived hyperpolarising factor and bradykinin-mediated release of prostacyclin $\left(\mathrm{PGI}_{2}\right)$ in the beneficial vascular effects of milk peptides ${ }^{(61)}$. However, prostanoids do not contribute to the local heating response in the cutaneous circulation ${ }^{(62)}$; thus, other methods would be required to assess the potential role of $\mathrm{PGI}_{2}$ in the vascular effects of dairy milk.

We chose to recruit healthy older individuals for this study because (1) our laboratory has previously shown a moderate age-related deficit in NO-dependent vasodilation in this population $^{(24,25)}$, and (2) this subject group represents a population that would most likely benefit from lifestyle modifications for the prevention of CVD. Other research in this area has focused on populations with overt $\mathrm{CVD}^{(63,64)}$. As such, it is possible that milk consumption has a more pronounced acute treatment effect on endothelial function in individuals with established vascular disease.

\section{Summary}

In summary, the local heating-induced vasodilatory response following dairy milk consumption was not different from the response following rice beverage consumption. Contrary to our hypothesis, NO-dependent vasodilation was decreased after dairy milk ingestion compared with rice beverage ingestion. 
This finding may be associated with a lower acute insulin response following dairy milk intake. Although dairy milk consumption did not acutely increase NO bioavailability, chronic dairy milk consumption may improve or protect endothelial function given the potential ACE-inhibitory and antioxidant properties, as well as the long-term reductions in blood pressure previously observed ${ }^{(2-6)}$.

\section{Acknowledgements}

The authors would like to express their gratitude for the assistance of Jane Pierzga, Susan Slimak, Dr Jody Greaney, Dr Jessica Kutz and Dan Craighead.

This research was supported by Dairy Management Inc.

L. M. A., W. L. K. and A. E. S. designed research; B. K. A. and A. E. S. conducted the research; A. E. S. analysed the data; and B. K. A. wrote the paper. All authors read and approved the final manuscript.

There are no conflicts of interest.

\section{References}

1. Heidenreich PA, Trogdon JG, Khavjou OA, et al. (2011) Forecasting the future of cardiovascular disease in the United States: a policy statement from the American Heart Association. Circulation 123, 933-944.

2. Toledo E, Delgado-Rodriguez M, Estruch R, et al. (2009) Low-fat dairy products and blood pressure: follow-up of 2290 older persons at high cardiovascular risk participating in the PREDIMED study. Br J Nutr 101, 59-67.

3. Wang L, Manson JE, Buring JE, et al. (2008) Dietary intake of dairy products, calcium, and vitamin $\mathrm{D}$ and the risk of hypertension in middle-aged and older women. Hypertension 51, 1073-1079.

4. Takashima Y, Iwase Y, Yoshida M, et al. (1998) Relationship of food intake and dietary patterns with blood pressure levels among middle-aged Japanese men. J Epidemiol 8, 106-115.

5. Alonso A, Beunza JJ, Delgado-Rodriguez M, et al. (2005) Low-fat dairy consumption and reduced risk of hypertension: the Seguimiento Universidad de Navarra (SUN) cohort. $A m J$ Clin Nutr 82, 972-979.

6. Djousse L, Pankow JS, Hunt SC, et al. (2006) Influence of saturated fat and linolenic acid on the association between intake of dairy products and blood pressure. Hypertension $\mathbf{4 8}$, 335-341.

7. Crichton GE, Elias MF, Dore GA, et al. (2012) Relations between dairy food intake and arterial stiffness: pulse wave velocity and pulse pressure. Hypertension 59, 1044-1051.

8. Livingstone KM, Lovegrove JA, Cockcroft JR, et al. (2013) Does dairy food intake predict arterial stiffness and blood pressure in men?: evidence from the Caerphilly Prospective Study. Hypertension 61, 42-47.

9. Tauzin J, Miclo L \& Gaillard JL (2002) Angiotensin-I-converting enzyme inhibitory peptides from tryptic hydrolysate of bovine alphaS2-casein. FEBS Lett 531, 369-374.

10. Nakamura Y, Yamamoto N, Sakai K, et al. (1995) Purification and characterization of angiotensin I-converting enzyme inhibitors from sour milk. J Dairy Sci $\mathbf{7 8}, 777-783$.

11. Pihlanto-Leppala A, Koskinen P, Piilola K, et al. (2000) Angiotensin I-converting enzyme inhibitory properties of whey protein digests: concentration and characterization of active peptides. J Dairy Res 67, 53-64.
12. Mullally MM, Meisel H \& FitzGerald RJ (1997) Identification of a novel angiotensin-I-converting enzyme inhibitory peptide corresponding to a tryptic fragment of bovine beta-lactoglobulin. FEBS Lett 402, 99-101.

13. Rival SG, Boeriu CG \& Wichers HJ (2001) Caseins and casein hydrolysates. 2. Antioxidative properties and relevance to lipoxygenase inhibition. J Agric Food Chem 49, 295-302.

14. Hernandez-Ledesma B, Davalos A, Bartolome B, et al. (2005) Preparation of antioxidant enzymatic hydrolysates from alpha-lactalbumin and beta-lactoglobulin. Identification of active peptides by HPLC-MS/MS. J Agric Food Chem 53, 588-593.

15. Suetsuna K, Ukeda $\mathrm{H}$ \& Ochi H (2000) Isolation and characterization of free radical scavenging activities peptides derived from casein. J Nutr Biochem 11, 128-131.

16. Hirota T, Ohki K, Kawagishi R, et al. (2007) Casein hydrolysate containing the antihypertensive tripeptides Val-Pro-Pro and Ile-Pro-Pro improves vascular endothelial function independent of blood pressure-lowering effects: contribution of the inhibitory action of angiotensin-converting enzyme. Hypertens Res 30, 489-496.

17. Stancliffe RA, Thorpe T \& Zemel MB (2011) Dairy attentuates oxidative and inflammatory stress in metabolic syndrome. Am J Clin Nutr 94, 422-430.

18. Zemel MB, Sun X, Sobhani T, et al. (2010) Effects of dairy compared with soy on oxidative and inflammatory stress in overweight and obese subjects. Am J Clin Nutr 91, 16-22.

19. Sacks FM, Willett WC, Smith A, et al. (1998) Effect on blood pressure of potassium, calcium, and magnesium in women with low habitual intake. Hypertension 31, 131-138.

20. Patki PS, Singh J, Gokhale SV, et al. (1990) Efficacy of potassium and magnesium in essential hypertension: a double-blind, placebo controlled, crossover study. BMJ 301, 521-523.

21. Green DJ, Maiorana AJ, Siong JH, et al. (2006) Impaired skin blood flow response to environmental heating in chronic heart failure. Eur Heart J 27, 338-343.

22. Holowatz LA \& Kenney WL (2007) Up-regulation of arginase activity contributes to attenuated reflex cutaneous vasodilatation in hypertensive humans. J Physiol 581, 863-872.

23. Hodges GJ, Nawaz S \& Tew GA (2015) Evidence that reduced nitric oxide signal contributes to cutaneous microvascular dysfunction in peripheral arterial disease. Clin Hemorheol Microcirc 59, 83-95.

24. Bruning RS, Santhanam L, Stanhewicz AE, et al. (2012) Endothelial nitric oxide synthase mediates cutaneous vasodilation during local heating and is attenuated in middle-aged human skin. J Appl Physiol (1985) 112, 2019-2026.

25. Minson CT, Holowatz LA, Wong BJ, et al. (2002) Decreased nitric oxide- and axon reflex-mediated cutaneous vasodilation with age during local heating. J Appl Physiol 93, 1644-1649.

26. Holowatz LA \& Kenney WL (2011) Oral atorvastatin therapy increases nitric oxide-dependent cutaneous vasodilation in humans by decreasing ascorbate-sensitive oxidants. Am J Physiol Regul Integr Comp Physiol 301, R763-R768.

27. Holowatz LA, Santhanam L, Webb A, et al. (2011) Oral atorvastatin therapy restores cutaneous microvascular function by decreasing arginase activity in hypercholesterolaemic humans. J Physiol 589, 2093-2103.

28. Abularrage CJ, Sidawy AN, Aidinian G, et al. (2005) Evaluation of the microcirculation in vascular disease. J Vasc Surg 42, 574-581.

29. IJzerman RG, de Jongh RT, Beijk MA, et al. (2003) Individuals at increased coronary heart disease risk are characterized by an impaired microvascular function in skin. Eur J Clin Invest 33, 536-542.

30. Briasoulis A, Tousoulis D, Androulakis ES, et al. (2012) Endothelial dysfunction and atherosclerosis: focus on novel therapeutic approaches. Recent Pat Cardiovasc Drug Discov 7, 21-32. 
31. Khan F, Patterson D, Belch JJ, et al. (2008) Relationship between peripheral and coronary function using laser Doppler imaging and transthoracic echocardiography. Clin Sci (Lond) 115, 295-300.

32. Coulon P, Constans J \& Gosse P (2012) Impairment of skin blood flow during post-occlusive reactive hyperhemy assessed by laser Doppler flowmetry correlates with renal resistive index. J Hum Hypertens 26, 56-63.

33. Khan F, Elhadd TA, Greene SA, et al. (2000) Impaired skin microvascular function in children, adolescents, and young adults with type 1 diabetes. Diabetes Care 23, 215-220.

34. Greaney JL, DuPont JJ, Lennon-Edwards SL, et al. (2012) Dietary sodium loading impairs microvascular function independent of blood pressure in humans: role of oxidative stress. J Physiol 590, 5519-5528.

35. Stanhewicz AE, Alexander LM \& Kenney WL (2015) Folic acid supplementation improves microvascular function in older adults through nitric oxide-dependent mechanisms. Clin Sci 129, 159-167.

36. Yamazaki $\mathrm{F}$ (2012) Oral vitamin $\mathrm{C}$ enhances the adrenergic vasoconstrictor response to local cooling in human skin. J Appl Physiol 112, 1689-1697.

37. Alkhatib A \& Klonizakis M (2014) Effects of exercise training and Mediterranean diet on vascular risk reduction in postmenopausal women. Clin Hemorheol Microcirc 57, 33-47.

38. Klonizakis M, Alkhatib A, Middleton G, et al. (2013) Mediterranean diet- and exercise-induced improvement in age-dependent vascular activity. Clin Sci 124, 579-587.

39. Astrup A (2014) Yogurt and dairy product consumption to prevent cardiometabolic diseases: epidemiologic and experimental studies. Am J Clin Nutr 99, 1235S-1242S.

40. Crichton GE \& Alkerwi A (2014) Dairy food intake is positively associated with cardiovascular health: findings from Observation of Cardiovascular Risk Factors in Luxembourg study. Nutr Res 34, 1036-1044.

41. Boutrou R, Gaudichon C, Dupont D, et al. (2013) Sequential release of milk protein-derived bioactive peptides in the jejunum in healthy humans. Am J Clin Nutr 97, 1314-1323.

42. Minson CT, Berry LT \& Joyner MJ (2001) Nitric oxide and neurally mediated regulation of skin blood flow during local heating. J Appl Physiol (1985) 91, 1619-1626.

43. Kellogg DL Jr, Liu Y, Kosiba IF, et al. (1999) Role of nitric oxide in the vascular effects of local warming of the skin in humans. J Appl Physiol (1985) 86, 1185-1190.

44. Kellogg DL Jr, Zhao JL \& Wu Y (2009) Roles of nitric oxide synthase isoforms in cutaneous vasodilation induced by local warming of the skin and whole body heat stress in humans. J Appl Physiol (1985) 107, 1438-1444.

45. Alexander LM, Kutz JL \& Kenney WL (2013) Tetrahydrobiopterin increases NO-dependent vasodilation in hypercholesterolemic human skin through eNOS-coupling mechanisms. Am J Physiol Regul Integr Comp Physiol 304, R164-R169.

46. Atkinson FS, Foster-Powell K \& Brand-Miller JC (2008) International tables of glycemic index and glycemic load values: 2008. Diabetes Care 31, 2281-2283.

47. Iredahl F, Tesselaar E, Sarker S, et al. (2013) The microvascular response to transdermal iontophoresis of insulin is mediated by nitric oxide. Microcirculation 20 , $717-723$.
48. de Jongh RT, Serne EH, IJzerman IJ, et al. (2008) Impaired local microvascular vasodilatory effects of insulin and reduced skin microvascular vasomotion in obese women. Microvasc Res 75, 256-262.

49. Rossi M, Maurizio S \& Carpi A (2005) Skin blood flowmotion response to insulin iontophoresis in normal subjects. Microvasc Res 70, 17-22.

50. Mah E \& Bruno RS (2012) Postprandial hyperglycemia on vascular endothelial function: mechanisms and consequences. Nutr Res 32, 727-740.

51. Sipola M, Finckenberg P, Vapaatalo H, et al. (2002) Alpha-lactorphin and beta-lactorphin improve arterial function in spontaneously hypertensive rats. Life Sci 71, 1245-1253.

52. Sanchez D, Kassan M, Contreras Mdel M, et al. (2011) Longterm intake of a milk casein hydrolysate attenuates the development of hypertension and involves cardiovascular benefits. Pharmacol Res 63, 398-404.

53. Ballard KD, Bruno RS, Seip RL, et al. (2009) Acute ingestion of a novel whey-derived peptide improves vascular endothelial responses in healthy individuals: a randomized, placebo controlled trial. Nutr J 8, 34 .

54. Yoshizawa M, Maeda S, Miyaki A, et al. (2010) Additive beneficial effects of lactotripeptides intake with regular exercise on endothelium-dependent dilatation in postmenopausal women. Am J Hypertens 23, 368-372.

55. Yamaguchi N, Kawaguchi K \& Yamamoto N (2009) Study of the mechanism of antihypertensive peptides VPP and IPP in spontaneously hypertensive rats by DNA microarray analysis. Eur J Pharmacol 620, 71-77.

56. Ballard KD, Mah E, Guo Y, et al. (2013) Low-fat milk ingestion prevents postprandial hyperglycemia-mediated impairments in vascular endothelial function in obese individuals with metabolic syndrome. J Nutr 143, 1602-1610.

57. Wong BJ \& Fieger SM (2010) Transient receptor potential vanilloid type-1 (TRPV-1) channels contribute to cutaneous thermal hyperaemia in humans. $J$ Physiol 588, 4317-4326.

58. Hodges GJ, Kosiba WA, Zhao K, et al. (2009) The involvement of heating rate and vasoconstrictor nerves in the cutaneous vasodilator response to skin warming. Am J Physiol Heart Circ Physiol 296, H51-H56.

59. Fieger SM \& Wong BJ (2010) Adenosine receptor inhibition with theophylline attenuates the skin blood flow response to local heating in humans. Exp Physiol 95, 946-954.

60. Wong BJ \& Minson CT (2011) Altered thermal hyperaemia in human skin by prior desensitization of neurokinin-1 receptors. Exp Physiol 96, 599-609.

61. Hirota T, Nonaka A, Matsushita A, et al. (2011) Milk caseinderived tripeptides, VPP and IPP induced NO production in cultured endothelial cells and endothelium-dependent relaxation of isolated aortic rings. Heart Vessels 26, 549-556.

62. McCord GR, Cracowski JL \& Minson CT (2006) Prostanoids contribute to cutaneous active vasodilation in humans. $A m \mathrm{~J}$ Physiol Regul Integr Comp Physiol 291, R596-R602.

63. de Leeuw PW, van der Zander K, Kroon AA, et al. (2009) Dose-dependent lowering of blood pressure by dairy peptides in mildly hypertensive subjects. Blood Press 18, 44-50.

64. Drouin-Chartier JP, Gigleux I, Tremblay AJ, et al. (2014) Impact of dairy consumption on essential hypertension: a clinical study. Nutr J 13, 83 . 